\title{
Control of WWV and WWVH Standard Frequency Broadcasts by VLF and LF Signals
}

\author{
B. E. Blair and A. H. Morgan \\ National Bureau of Standards, Boulder, Colo.
}

(Received October 21, 1964; revised January 22, 1965)

\begin{abstract}
Since 1961 the NBS VLF and LF signals have improved the calibration and frequency control of the WWV (Maryland) HF broadcasts. Similarly, better control of the WWVH (Hawaii) HF broadcasts was achieved in early 1963 by monitoring the NBS VLF broadcasts in terms of the WWVH control oscillator. In mid $1963 \mathrm{WWVL}(20 \mathrm{kc} / \mathrm{s})$ and WWVB $(60 \mathrm{kc} / \mathrm{s})$ were relocated from two sites near Boulder, Colo., to a single site near Ft. Collins, Colo., and the transmitter power for both broadcasts was increased several fold. These higher powered broadcasts resulted in more precise control of both HF broadcasts. Through the VLF and LF signals the 24-hr average frequency values of WWV are related to the United States Frequency Standard (USFS) within a few parts in $10^{11}$.

This paper describes the NBS low-frequency broadcasts, the method of using them to control and calibrate the HF broadcasts, and gives an analysis of the precision of frequency control obtained at WWV over a 21-month period. An appendix discusses the short-term phase stabilities and diurnal phase shifts observed in the low-frequency signals at WWV and WWVH, and examines the accuracylimiting effects of propagation path characteristics and background noise levels in such received signals.
\end{abstract}

\section{Introduction}

The accuracy of the United States Frequency Standard (USFS) has improved greatly over the last four decades from approximately one part in $10^{4}$ in 1920 to a present value of 5 parts in $10^{12}$. One way such technological advances have met the needs of science and industry is through the NBS standard frequency broadcasts, as graphically shown in figure 1.

TYPE OF

STANDARD

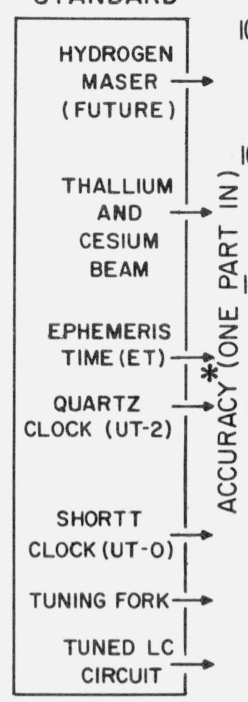

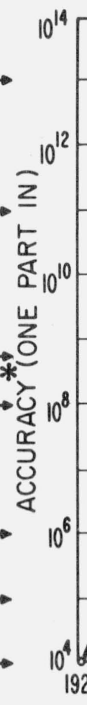
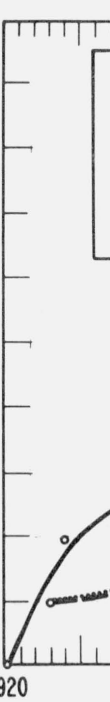

|11 WITH RESPECT TO THE ACCEPTED ASTRONOMICAL STANDARDS;

SINCE 1957 IT IS SHOWN, FOR REASONS OF EMPHASIS, WITH RESPECT TO THE UNPERTURBED Cs RESONANCE

LOW FREQUENCY BROADCASTS USFS The RECE

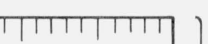

The abrupt change in the slope of the curve in 1957 was due to a technological "breakthrough" culminating in commercial, atomic frequency standards. Laboratory models of atomic (cesium-beam) frequency standards were developed and built at NBS and in 1960 two such units became the basis of the USFS [Mockler et al., 1960]; continued improvements followed [Beehler et al., 1962] and are reflected in figure 1. By late 1961 the NBS low power WWVL $(20 \mathrm{kc} / \mathrm{s})$ and

MAJOR USER 
WWVB $(60 \mathrm{kc} / \mathrm{s})$ broadcasts disseminated the USFS with a transmitted accuracy of several parts in $10^{11}$ (fractional frequency units) through control by transfer (working) atomic frequency standards. Regularly published corrections relate such values to the USFS as shown in figure 1 .

Prior to 1961, WWV was calibrated at NBS, Boulder, by comparing received WWV time signals with the USFS, and was frequency controlled on the basis of these calibrations. This technique, briefly described in a previous publication [Watt et al., 1961], will not be discussed here except to note that the precisions achieved, using the HF time signals alone, were several parts in $10^{10}$ for 30 -day running averages. Similarly, until early 1963, calibration and control of the WWVH broadcasts relied on the WWV time signals as received in Hawaii. Because of the inadequacy of this method, a new technique was introduced at WWV in January 1961, using the NBS low-frequency signals received from WWVL and WWVB. It is well known that the received phase stability of VLF and $L F$ radio signals at large distances is several orders of magnitude better than that of HF [Pierce, 1958; Crombie et al., 1958; Watt et al., 1961] and that the VLF signals propagate over large distances with small attenuation. Thus, such characteristics of the NBS low-frequency signals enabled the calibration and control of the HF broadcasts with a precision nearly equivalent to the stability of atomic frequency standards.

The improvement in the WWV frequency control is evident in figure 2 where the monthly means are plotted for 4 years. The variances, $S^{2}$, are pooled estimates obtained from monthly daily values which are based on running averages for the indicated periods.
For the period 1960 to 1963 the standard deviations, $S$, decrease from 1.2 to 0.31 parts in $10^{10}$. For WWVH the improvement is a little less as evidenced by figure 3. Clearly shown, however, is the smaller variation in the WWVH monthly means that occurred with the initiation of VLF control in March 1963.

This paper will describe the NBS standard frequency broadcasts; the method of using the NBS lowfrequency signals for calibration and control of the HF broadcasts; the relative agreement between the received 20 and $60 \mathrm{kc} / \mathrm{s}$ signals at $\mathrm{WWV}$; and the effects of increased WWVL and WWVB transmission power. Variations in short-term phase stabilities and diurnal phase shifts, observed in low-frequency recordings at WWV and $\mathrm{WWVH}$, are given in the appendix.

\section{NBS Standard Frequency Broadcasts}

WWVL and WWVB, presently located at Ft. Collins, Colo., lie nearly on a great circle path between WWV at Greenbelt, Md., and WWVH at Maui, Hawaii. WWVH is over twice as far $(5300 \mathrm{Km})$ from Ft. Collins as is WWV $(2400 \mathrm{Km})$. The HF broadcasts of WWV are at $2.5,5,10,15,20$, and $25 \mathrm{Mc} / \mathrm{s}$ while those at WWVH are at 5,10 , and $15 \mathrm{Mc} / \mathrm{s}$; characteristics of the NBS radio stations have been given previously [Morgan, 1962 and 1963; Richardson, 1964].

\subsection{Role of Frequency Standards in NBS Broadcasts}

The frequency reference of the NBS standard frequency broadcasts is the USFS which consists of two cesium beam units [Mockler et al., 1960] designated as NBS-I and NBS-II. Because these do not operate continuously, the U.S. Working Frequency Standard

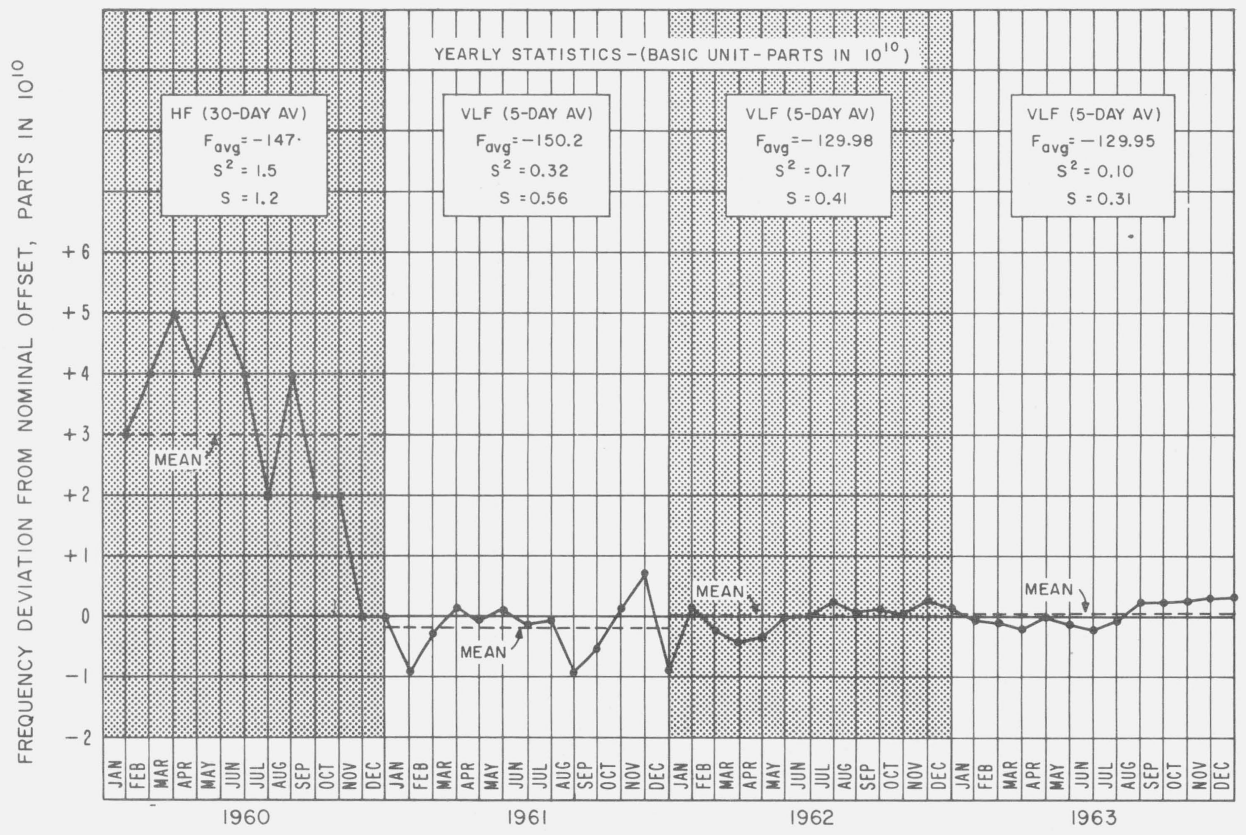

FIGURE 2. Improvements in the frequency control of $W W V$. (Ordinate in fractional frequency). 


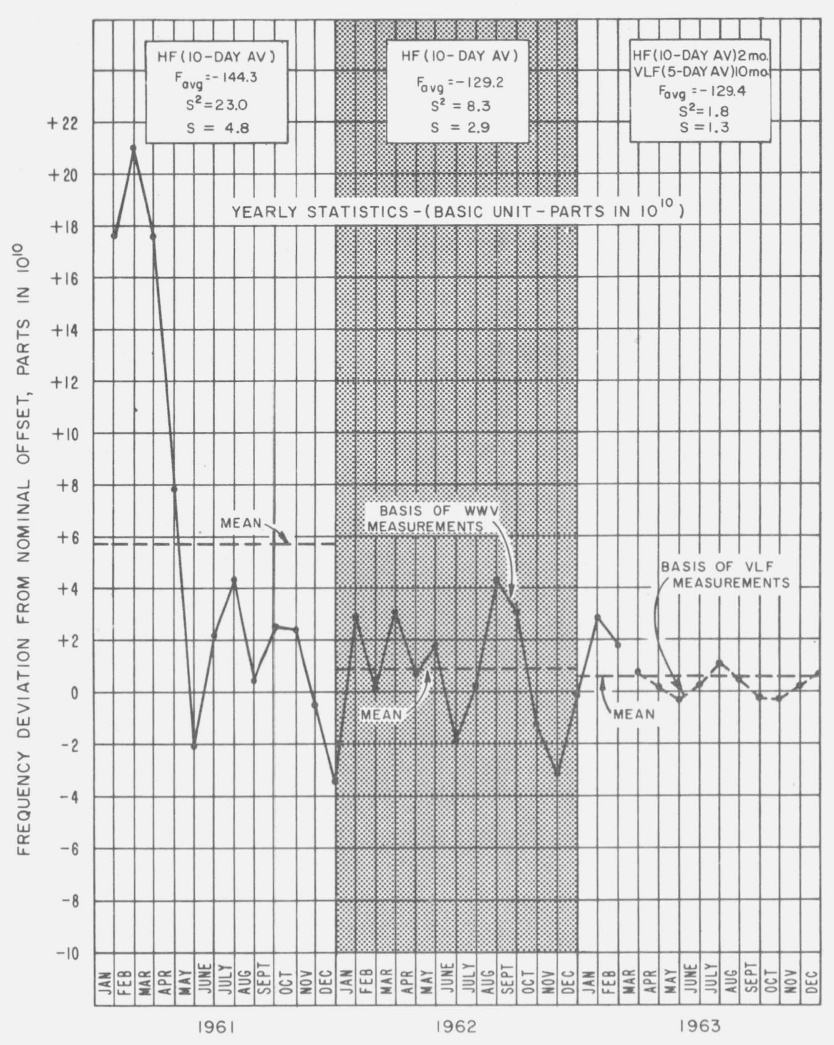

FigurE 3. Improvements in the frequency control of WWVH. (Ordinate in fractional frequency).
(USWFS), consisting of a group of oscillators, provides continuity in the calibration and frequency control of the NBS standard frequency broadcasts. Figure 4 shows the relationship of the USWFS to the USFS and the function of the former in controlling NBS stations WWV, WWVH, WWVL, and WWVB.

To improve the transmitted stability of the $20 \mathrm{kc} / \mathrm{s}$ signals, in October 1961 a remote phase-locking system, operating at VHF, was placed into operation between Boulder and WWVL when this station was located at Sunset, Colo. [Fey et al., 1962]. A similar system now controls the low-frequency broadcasts from the new Ft. Collins site [NBS, 1963]. The phase-lock system continuously keeps the transmitted phase of both the WWVL and WWVB signals in agreement with that of the USWFS at the Boulder Laboratories. Such a system corrects for frequency drift of the oscillator which controls the transmitter as well as for phase fluctuations introduced by the transmitter or antenna system in the broadcast signals. Measurements indicate that the transmitted low-frequency stability (standard deviation) is essentially that of the USWFS, which in the case of rubidium standards is equal to or less than 2 parts in $10^{11}$ [Blair et al., 1965].

\subsection{Description of NBS VLF Broadcasts}

NBS began broadcasting a low power, standard 20 kc/s on April 5, 1960 [NBS, 1960], from Sunset, Colo. (18 km from NBS, Boulder). This was the first known standard frequency broadcast at $20 \mathrm{kc} / \mathrm{s}$ [the specific frequency adopted for such use by the International Telecommunications Union (ITU) in December 1959].

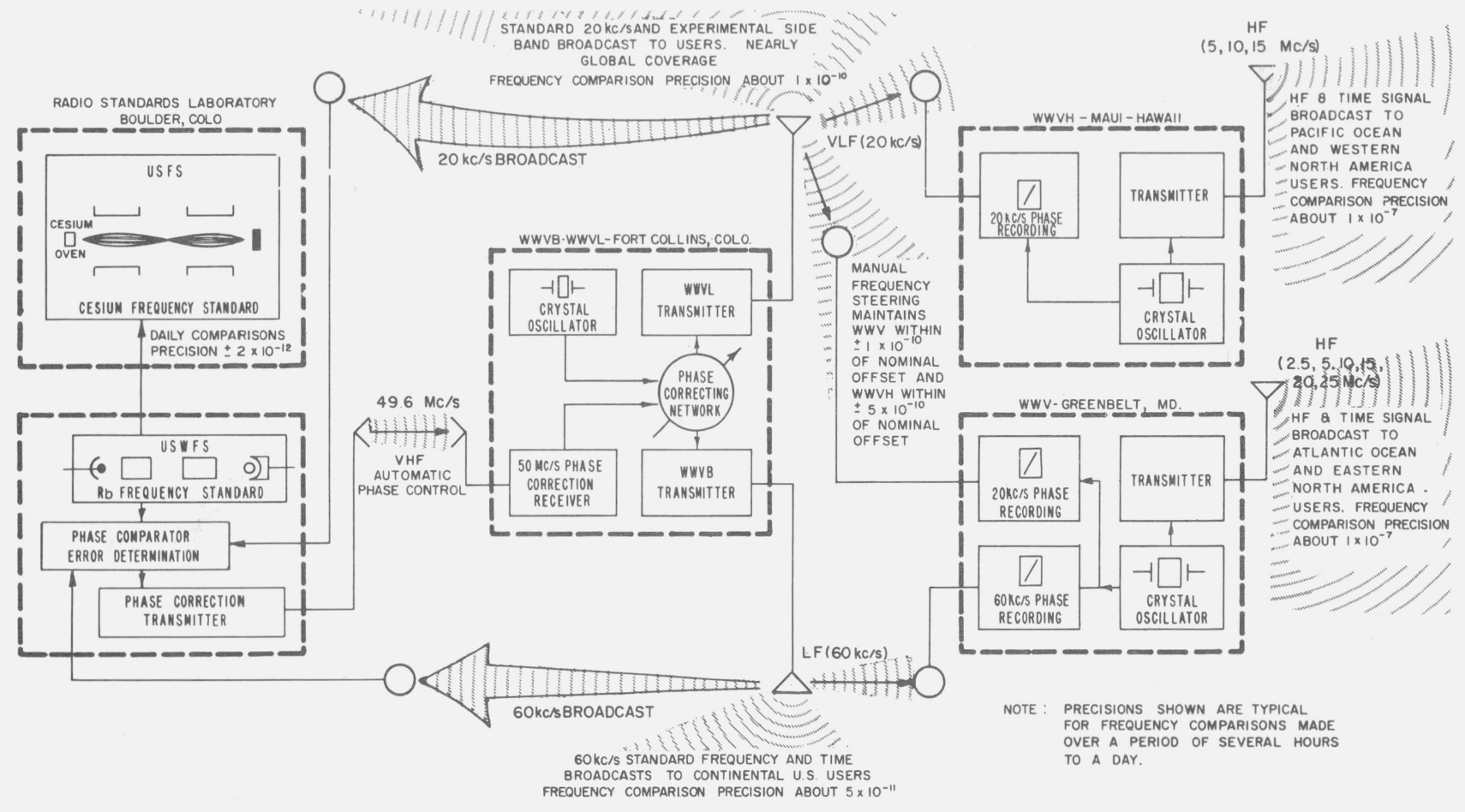

FIGURE 4. USFS reference and frequency control of NBS standard frequency broadcasts. 
Great Britain, however, has pioneered in broadcasting standard frequency signals in both VLF and LF bands. The Sunset station operated for nearly $3 \frac{1 / 2}{2}$ years, and was relocated with modified equipment at Fort Collins, Colo., August 1963 [NBS, 1963; Richardson, 1964]. This new station (WWVL-latitude $40^{\circ} 40^{\prime} 51^{\prime \prime} \mathrm{N}$ longitude $105^{\circ} 03^{\prime} 00^{\prime \prime} \mathrm{W}$ ) provided a much larger antenna and more powerful transmitter; thus, the radiated power was increased from $15 \mathrm{~W}$ to about $1 \mathrm{~kW}$.

\subsection{Description of NBS LF Broadcasts}

In 1956 a standard $60 \mathrm{kc} / \mathrm{s}$ broadcast was begun from the grounds of NBS at Boulder, Colo. [NBS, 1957]. The call letters KK2XEI were used initially but were changed to WWVB in March 1960. Because of the low power (about $2 \mathrm{~W}$ radiated) these signals were of limited use. Nevertheless, station WWV received such signals and confirmed the stability of LF signals as propagated over long distances. A rubidium atomic frequency standard directly controlled the $60 \mathrm{kc} / \mathrm{s}$ broadcast from August 1961 to June 1963. Casual checks revealed no appreciable errors introduced into the broadcasts through antenna and/or transmitter variations, although the WWVB signals were not continuously phase-locked to the USWFS during this period. On July 5, 1963, WWVB (latitude $40^{\circ} 40^{\prime} 28^{\prime \prime}$ $\mathrm{N}$-longitude $105^{\circ} 02^{\prime} 39^{\prime \prime} \mathrm{W}$ ) began radiating about 5 $\mathrm{kW}$ of power from the new station at Ft. Collins, Colo.

\section{Calibration and Frequency Control of the HF Broadcasts}

Calibration of the WWV broadeasts since 1961 consists of relating the WWV daily frequency values to the USFS through the NBS low-frequency received signals. For frequency control of the WWV broadcasts, such signals also indicate when adjustments of the controlling oscillator are necessary to maintain the HF broadcast frequency within set limits. ( \pm 1 part in $10^{10}$ of nominal for $\mathrm{WWV}$ ). The frequency measurements at the HF stations are obtained with conventional, phase-lock receiving systems [Looney, 1961; Morgan et al., 1961]. The overall effective bandwidth of the tracking-receiver systems employed at WWV in Maryland is about $0.001 \mathrm{c} / \mathrm{s}$, and the sensitivity is between 0.1 and $1 \mu \mathrm{V}$. The system can follow a maximum frequency difference of about 2 parts in $10^{8}$ between an incoming signal and the local standard, (i.e., about $1 \mu$ sec of equivalent phase difference per minute). At WWVH, in Hawaii, the VLF tracking receiver has an effective bandwidth of $0.006 \mathrm{c} / \mathrm{s}$ and a sensitivity near $0.01 \mu \mathrm{V}$.

The concept of the frequency control for WWV and WWVH is portrayed also in figure 4. This method of control relies on a manual link between the phaselock receiving systems and the controlling oscillator at the HF stations. At WWV, the phase of both the WWVL and WWVB signals is recorded continuously in terms of the controlling oscillator; the accumulated phase differences are read daily at 24-hr intervals when the sun is at high noon over the center of the path (1800 UT). At the Boulder Laboratories these observations are used to compute the WWV frequency in terms of the USFS. Such assigned daily values provide the calibration of the WWV broadcasts. To smooth out day-to-day variability, a 5-day running average of the WWV daily frequency is calculated for each day, and such values are published monthly in the PROCEEDINGS-IEEE. The WWVH values are related to the USFS similarly through the WWVL signals.

\section{Typical VLF Signal Phase Recordings}

Figures 5, 6, and 7 show typical recordings of lowfrequency signals as received at stations WWV and WWVH. (NBA signals have been used for spot checks, and a typical recording made at WWV is shown in fig. 5.) It is from such records that the accumulated phase is measured at 24-hr intervals. The diurnal variations shown in these records are of considerable interest. Rapid phase shifts occurring at both sunrise and sunset are caused by changes in the ionospheric-reflection height. (Such height changes have been interpreted through mode theory [Wait, 1962].) The shape of the transitions at $20 \mathrm{kc} / \mathrm{s}$ is worth noting. At sunrise, the reflection height begins to drop and the phase of the received signals first decreases by 5 to $10 \mu \mathrm{sec}$ and then increases to the average daytime value. At sunset an initial decrease is followed by a short increase in phase with a gradual decrease to the nighttime level. Such changes are very regular and repeat with consistency from day to day. This behavior presumably results from mode interference effects at this frequency over this path [Wait, 1963; Crombie, 1964]. Although this is not seen on the $60 \mathrm{kc} / \mathrm{s}$ records at $\mathrm{WWV}$, another characteristic frequently appears: one cycle, or an integral multiple of one cycle, of the received signal is lost during the sunrise period. This is shown in the WWVB recordings of June 5 and October 10 in figures 5 and 6 . In figure 5 a dashed curve has been drawn, indicating where the analog recording of the phase should have been. Such behavior can result from destructive interference between several rays with changing amplitude and phase [Burtt, 1963]. A similar effect at sunset has been reported for the 60 $\mathrm{kc} / \mathrm{s}$ signals as received at Austin, Tex. [Tracor, 1964]. Short-term phase stabilities and diurnal phase changes, obtained from low-frequency phase recordings made at WWV and WWVH, are tabulated in the appendix.

\section{Relative Agreement Between Received 20 and $60 \mathrm{kc} / \mathrm{s}$ Signals-Effects at WWV of VLF and LF Transmission Power}

The VLF-LF method of calibration and control is predicated upon the relative phase stability and frequency agreement between the received 20 and $60 \mathrm{kc} / \mathrm{s}$ signals. Since frequency is the time rate of change of phase, frequency values may be derived from phase measurements. A discussion of the agreement between the received frequencies, coupled with an 

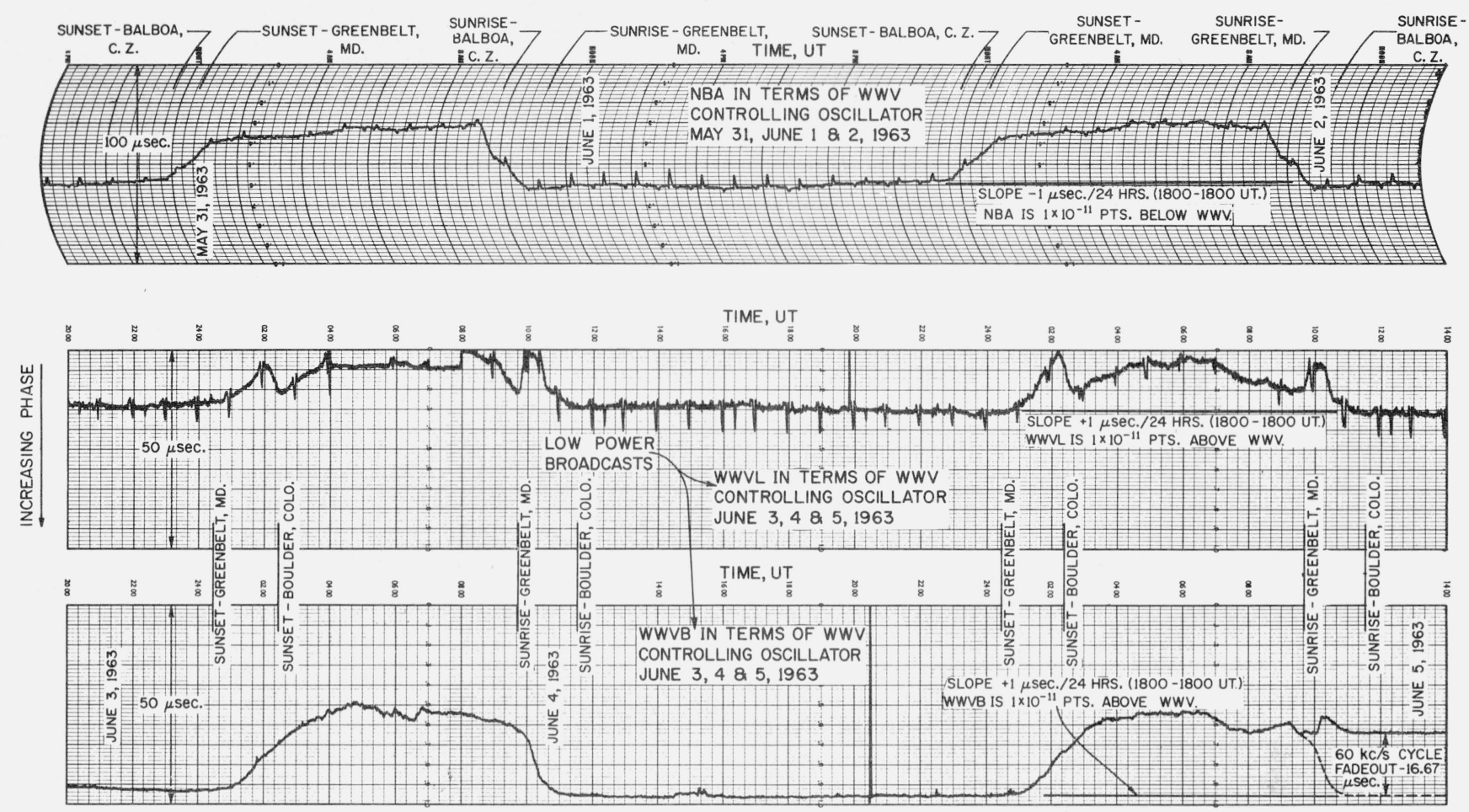

FigURE 5. Typical records of NBA, WWVL and WWVB (low power) as received at station WWV-June 1963.



FIGURE 6. Typical records of WWVB and WWVL (high power) as received at station WWV-October 1963.

evaluation of the effects of increased transmission power of the Ft. Collins broadcasts, follows.

\subsection{Comparison of WWV Frequency in Terms of 20 and $60 \mathrm{kc} / \mathrm{s}$ as Received at WWV}

The average daily frequency of $\mathrm{WWV}$ as determined by received VLF and LF NBS signals is shown in figures 8 and 9 for both low- and high-power transmission periods in October 1962 and 1963, respectively. As can be seen, good agreement exists. For comparison,
NBA data are shown in figure 8 . In both figures, the variation in the WWVB values is smaller than that for WWVL, and the 1963 combined groupings show a lesser variation than the corresponding 1962 data. Because the same oscillator was used at WWV in both instances, the improvement in the data is believed to result, at least in part, from the higher power signals. The scatter about the least square lines, shown by the standard error of estimate, $\mathrm{S}_{\mathrm{y} / \mathrm{x}}$ [Crow et al., 1960], results presumably from oscillator variations at $\mathrm{WWV}$, with small contribution from propagation effects and 




Figure 7. Typical records of WWVL as received at station WWVH (Maui)-June and October 1963.

measurement errors. Note that in 1963, figure 9, there appears to be a very high correlation between the 20 and $60 \mathrm{kc} / \mathrm{s}$ points in the combined plot. Since the WWVL and WWVB broadcasts at Ft. Collins are controlled by a common oscillator, the correlated variation noted in these points, as referred to the same WWV oscillator, is felt to result either from fluctuations in the WWV controlling oscillator, common propagation effects, or both. Such good agreement does not always occur as is shown later in the NovemberDecember data.

\subsection{Daily Agreement Between Received 20 and 60 $\mathrm{kc} / \mathrm{s}$ Signals at WWV}

The average daily frequency differences between the WWVL and WWVB signals as received at station WWV have been divided into two groups for a 21month period of study: period 1 covers the low-power broadcasts from April 1, 1962 to June 30, 1963; period 2 includes the high-power broadcasts from July 1 to December 30, 1963. (The low-power $20 \mathrm{kc} / \mathrm{s}$ signals and high-power $60 \mathrm{kc} / \mathrm{s}$ signals were used to obtain the July 1963 data.) The agreement between WWVL and WWVB as received at WWV is shown by the difference in nominal offset between the two broadcasts.

Figure 10 shows the daily variations in offset frequency differences for the two periods. Figures 11 and 12 give plots of monthly average differences $\bar{X}$, and standard deviations, $S_{d}$, for the 21-month period. The variation of these statistics in figures 10 through 12 shows a definite decrease for the period 2 data. Also apparent is the increased variability in November 1962 and November-December 1963. The cause of such variation is unknown at this time, although seasonal propagational effects likely are major contributing factors.

Figure 13 gives histograms of the two data groups. The grand mean offset differences, $\vec{X}_{1}$ and $\overline{\bar{X}}_{2}$, between WWVL and WWVB as received at WWV are negligible for both levels of power transmission. Still, the period 2 average standard deviation, $S_{d 2}$, reduces to about half that for period 1. (The November 1962 and November-December 1963 data were omitted in com- puting these statistics on the basis of nonhomogeneity of their variances [Box, 1953].) The lesser variation for period 2 may result from at least three factors: (1) The better signal to noise ratio of the high power Ft. Collins broadcasts permitted more reliable phase tracking at WWV; (2) during period 1 the WWVB signals, although directly controlled by an atomic standard, were not continuously phase-locked to this USWFS. Thus, small offset differences may have existed between these low-power WWVL and WWVB signals as broadcast; and (3) during period 2, as noted before, there was essentially a constant frequency difference between the WWVL and WWVB signals as broadcast.

Superimposed on the histograms in figure 13 are fitted normal curves based on statistics of the observed samples. As can be seen, the general form of the histograms is somewhat similar to that of the normal curve but with a greater central tendency or high frequency of values near the mean. Significant departure from normality was found, as expected, for both periods by a chi ${ }^{2}$ statistical test. In addition, a curve type criterion, $\beta_{2}$, was calculated for each data group. ( $\beta_{2}$ is the ratio of the sample 4 th moment about the mean to the sample variance squared. This ratio equals 3.0 for the normal distribution.) Values of $\beta_{2}$ equal to 3.5 and 7.5 were obtained for periods 1 and 2 respectively. Such values, greater than 3.0, are in agreement with the concentration of the data about the mean.

The statistical limits shown in figure 10 through 12 are based on a normal distribution and independence of the individual observations. The importance of this latter factor will be considered in subsequent studies, while a discussion of the effects of a nonnormal distribution follows. Figure 10 shows tolerance limits [Crow et al., 1960] for the daily offset differences. Nonparametric tolerance limits [Somerville, 1958], were computed also and gave results not significantly different from those based on a normal distribution. Thus, although the tolerance limits as shown are not strictly justified, they are at least approximately correct. 

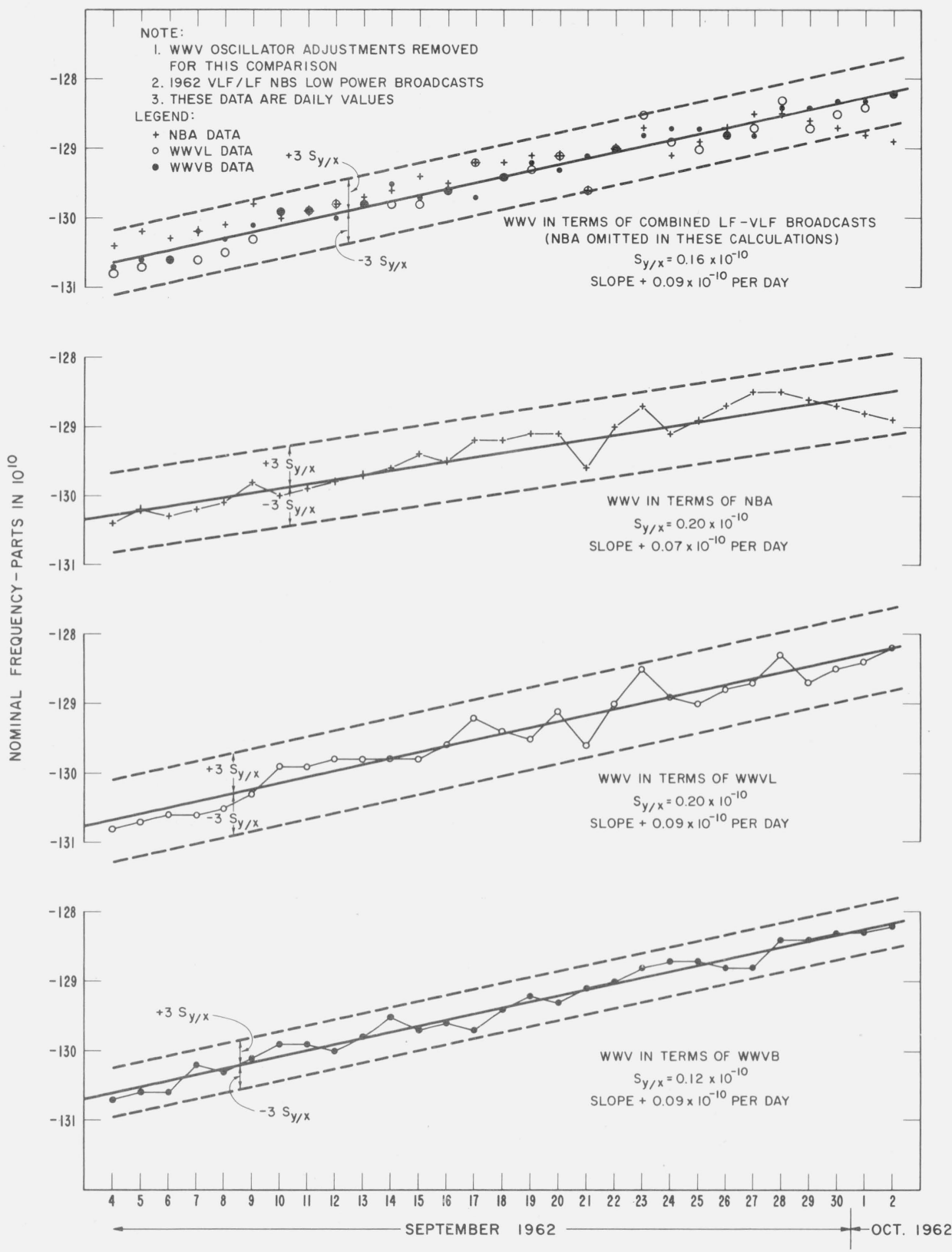

Figure 8. Comparison of $V L F / L F$ determinations of $W W V$ frequency (low power-1962).

Confidence limits shown in figure 11, about the monthly offset differences, $\bar{X}$, also are believed to be reasonable, since the means of even small samples essentially are normally distributed even if the basic data are not [Davies, 1957]. On the other hand, confidence limits for standard deviations are quite dependent upon a normal distribution of the parent data. Thus, such confidence limits, shown in figure 12 , should be used with caution.

\section{VLF Measurements at WWVH}

The calibration and frequency control of the WWVH broadcasts by the $20 \mathrm{kc} / \mathrm{s}$ signals is largely experimental at this time, although significant improvements have been obtained since their introduction in April 1963. In figure 14 the WWVH frequencies, in terms of the WWVL broadcasts, are seen to agree generally with 30-day running averages based on WWV HF meas- 


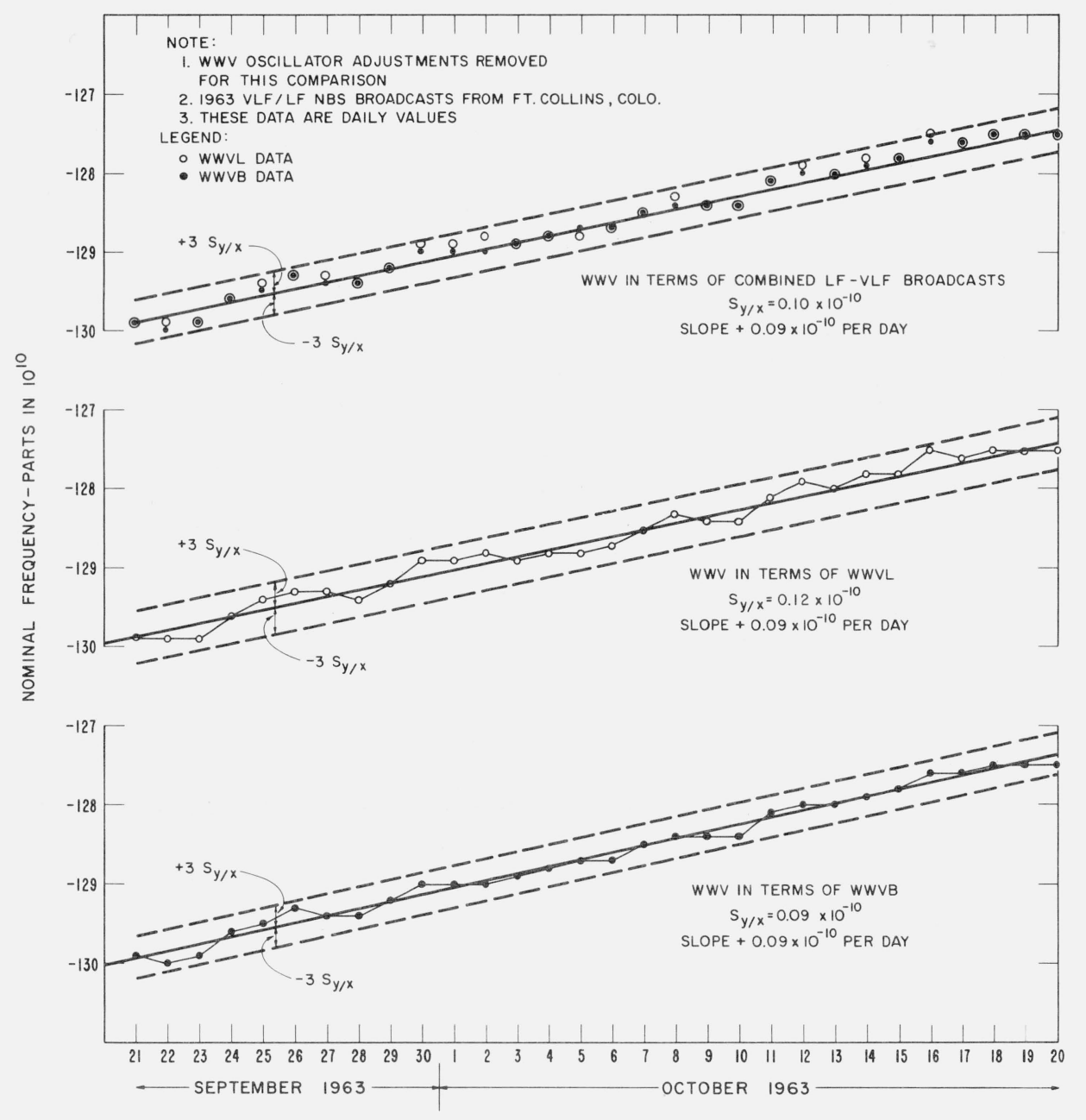

FIGURE 9. Comparison of VLF/LF determinations of WWV frequency (high power-1963).

urements for a period in May-June 1963. (The WWV HF values for this same period are included for comparison.) The running average procedure clarifies the general trend of a variable set of measurements sensitive to time by smoothing the short-term, or dayto-day fluctuations. The large daily variations in the WWVH data presumably result from fluctuations in the WWVH controlling oscillator. It is expected that the WWVH broadcasts will eventually have a stability equivalent to that of WWV through the use of the low-frequency signals from $\mathrm{Ft}$. Collins.

\section{Calibration and Frequency Control Results}

Measurements made at station WWV for a 21-month period of time indicated only negligible bias in the average offset difference between the WWVL and WWVB received signals; also, the standard deviation of the average daily differences was about 1 or 2 parts in $10^{11}$. In other words, this was the net effect of all variation producing influences such as propagation effects and instrument errors. Tolerance limits for including 90 percent of the daily variations at WWV with a probability of 95 percent are near \pm 4 parts in $10^{11}$ and such values indicate the calibration uncertainty during this period. The day-to-day frequency variations of the controlling oscillator at WWV are near several parts in $10^{11}$. Such fluctuations would be present of course in the WWV transmitted signals.

This method of calibration and frequency control by NBS low-frequency signals would be equally applicable to other $\mathrm{HF}$ or similar broadcasts requiring such accuracy. (The HF station ZUO, in South Africa, presently frequency controls its broadcasts by the WWV HF signals [CCIR, 1963].) The dissemination of the USFS through these low-frequency broadcasts provides a readily available reference directly traceable to NBS.

\section{Conclusions}

Improvement in the NBS HF broadcasts since 1961 has resulted from frequency-steering by the NBS low- 


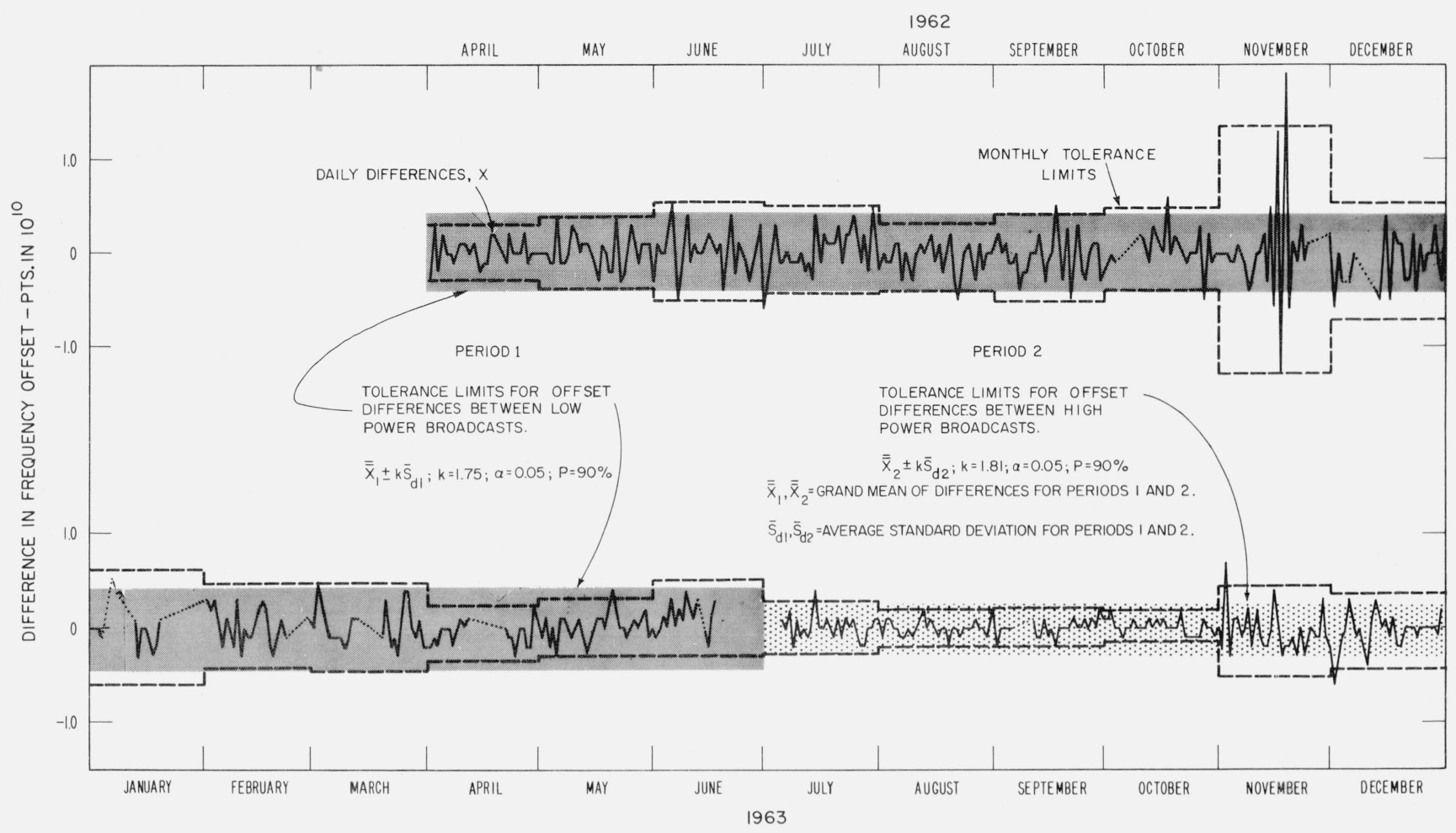

FIGURE 10. Daily variations in offset differences between WWVL and WWVB as received at station WWV.

frequency signals. The stability of the HF broadcasts is nearly equivalent to that of the received VLF and $\mathrm{LF}$ signals. The higher power broadcasts from $\mathrm{Ft}$. Collins give results at WWV which are less variable and closer to the offset frequency of the USWFS than the former low-power broadcasts. The nonnormality of the WWVL and WWVB difference data was manifested by a strong central tendency about the mean; this, however, with the exception of confidence limits for standard deviations, has small effect on the computed statistical limits. VLF and LF standard frequency broadcasts can be used to control HF broadcasts with a precision of several parts in $10^{11}$.

\section{Appendix. VLF and LF Propagation Data}

In the course of calibrating and controlling the HF broadcasts, VLF and LF propagation data was obtained. This appendix presents a study of the shortterm phase stability and diurnal phase shifts observed in low-frequency signals received at WWV and WWVH. Knowledge of propagation variations over diverse paths is a matter of increased concern in fields such as frequency and time dissemination [Looney, 1964] and long-range navigational aids [Pressey et al., 1961; Blackband, 1964].

\subsection{VLF and LF Short-Term Phase Stability}

The phase stability of some VLF and LF signals was analyzed for several 10-day periods in October 1962 and June/October 1963. The data involved the WWVL, WWVB, and NBA signals, as received at stations WWV and WWVH. Measurements on the phase recordings consisted of fitting a least square line to phase points taken at $1 / 2$-hr intervals for either all daylight or all darkness on the path for a given day; calculating the daily standard error of estimate about this fitted line; and, averaging these daily standard error of estimates to obtain the mean variation, $S_{\text {avg (ph), }}$ for each 10-day period. A summary of these statistics is given in table 1 . Several interesting observations can be made from these data: (1) The LF stability appears to be considerably better than that for the VLF measurements during the daytime; (2) the nighttime variations for both frequency bands are comparable; (3) in each frequency band, fluctuations during the daytime are much less than those at night; and, (4) generally, some improvement in phase stability is associated with the NBS high power low-frequency broadcasts.

Phase fluctuations observed at a receiver output result from a combination of effects, due to: (1) The 


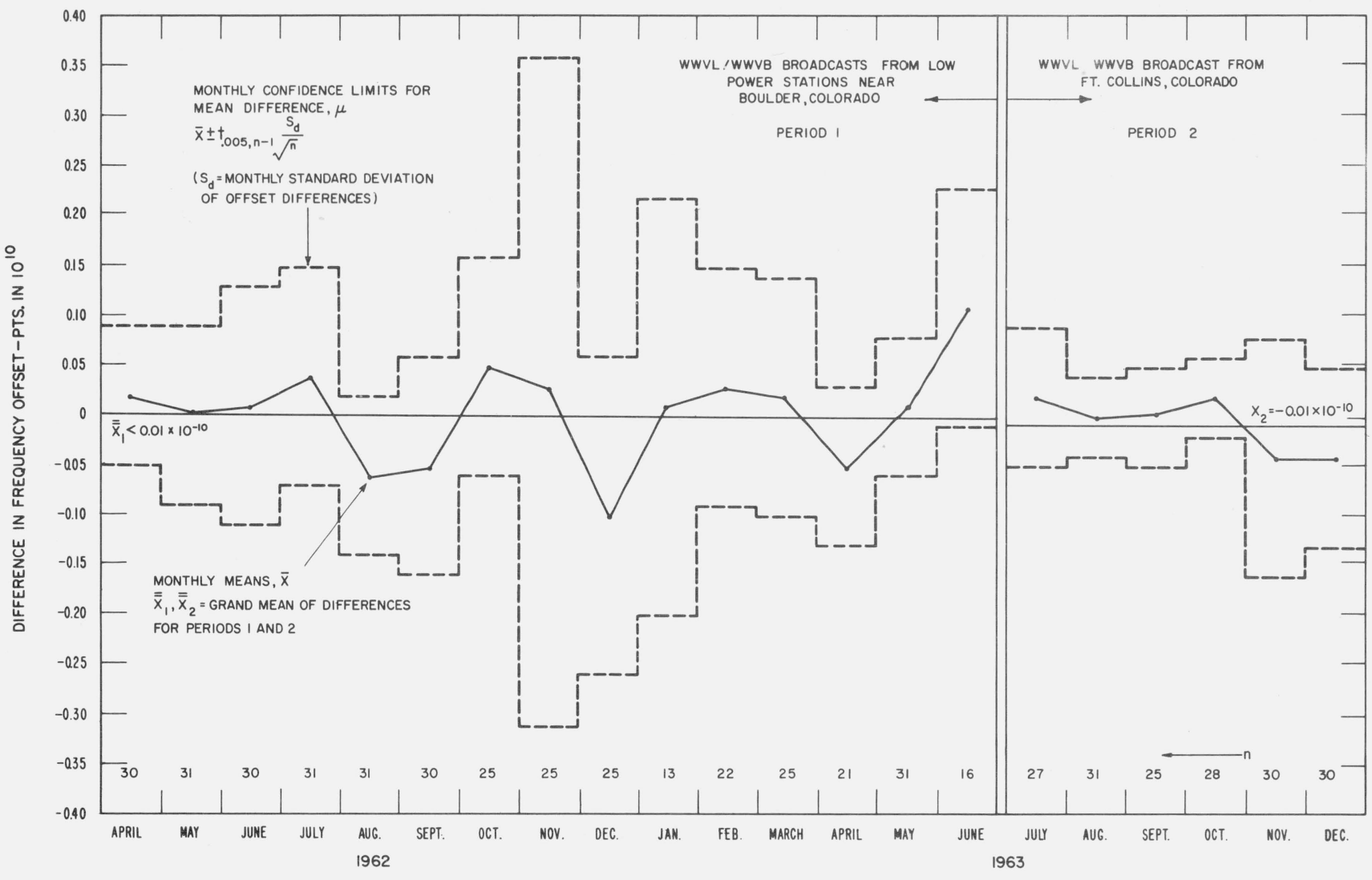

CONFIDENCE LIMITS FOR $\mu(99 \%$ P) MONTHLY DIFFERENCES BETWEEN WWVL AND WWVB AS RECEIVED AT STATION WWV

FIGURE 11. Monthly average offset differences between WWVL and WWVB as received at station WWV.

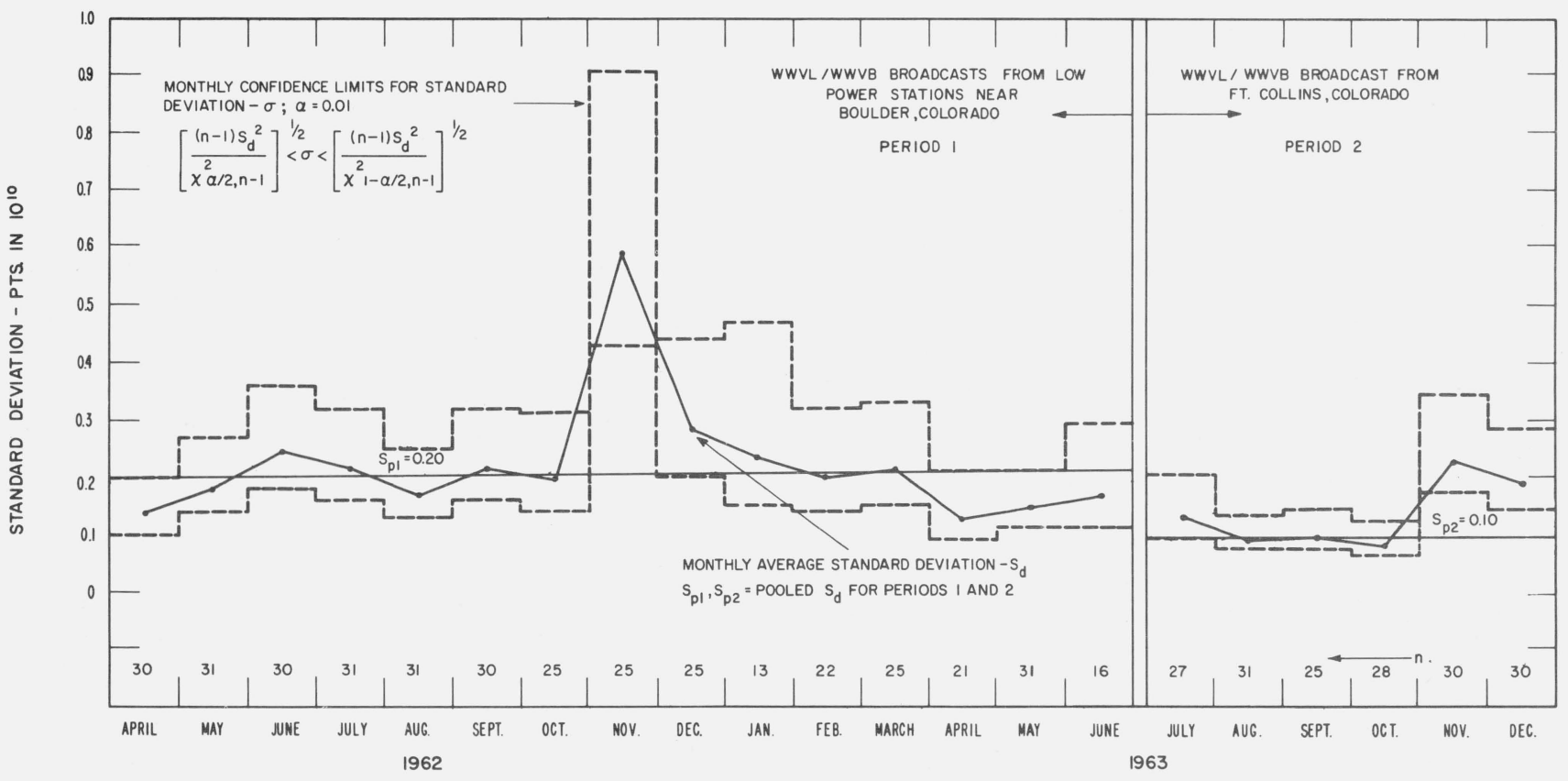

CONFIDENCE LIMITS FOR $\sigma(99 \% P)$ MONTHLY DIFFERENCES BETWEEN WWVL AND WWVB AS RECEIVED AT STATION WWV

FIGURE 12. Monthly average standard deviations of offsets between WWVL and WWVB as received at station WWV. 

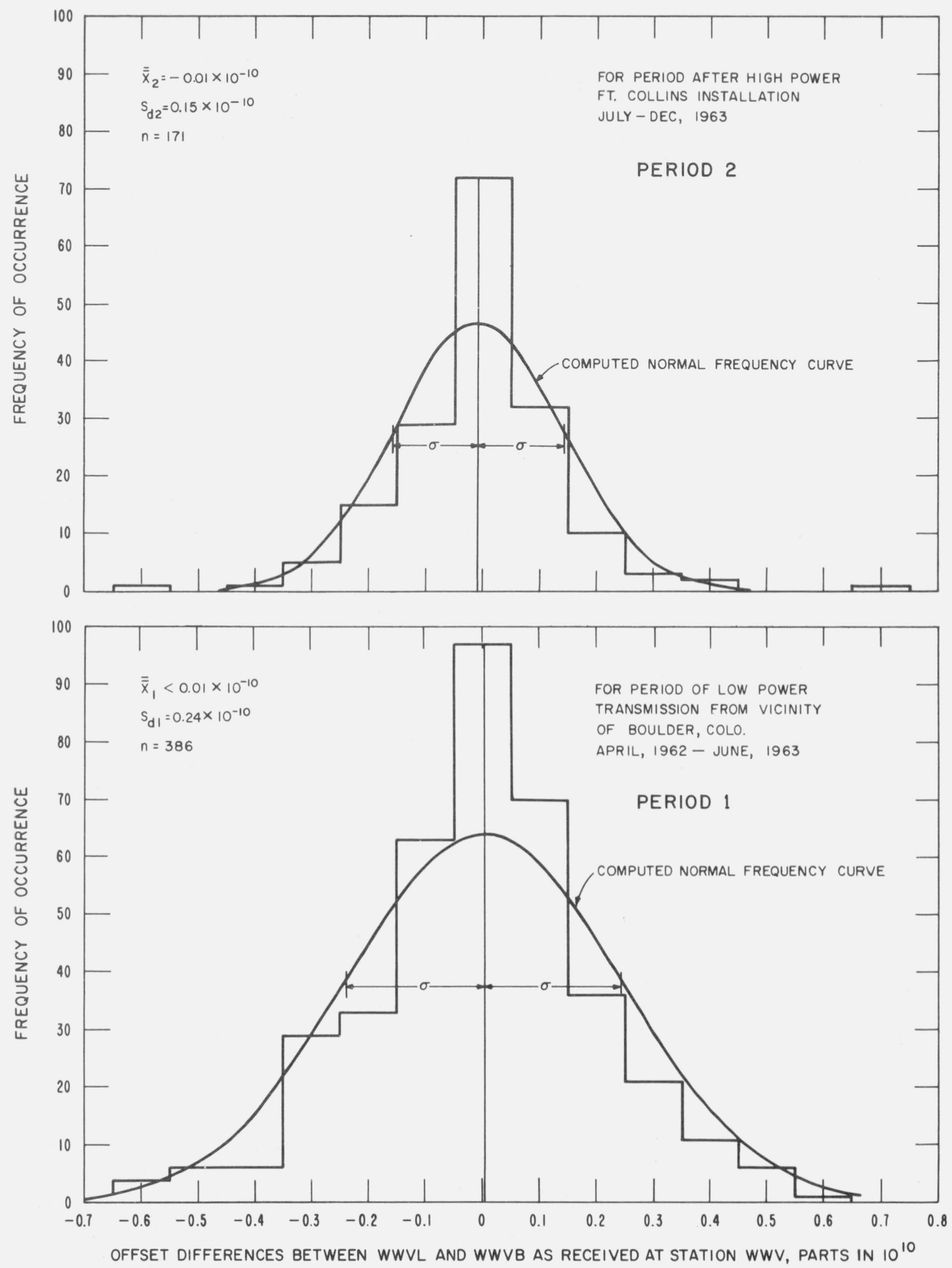

FiguRE 13. Histograms of $W W V L / W W V B$ offset differences for low power and high power broadcasts.

transmitting system; (2) the propagation medium; (3) atmospheric and other types of noise; and (4) the receiving system. The standard deviations of short time fluctuations in the transmitted phase of the WWVL and WWVB signals is believed to be about 0.1 $\mu$ sec. Since the receiving systems employed also introduce phase errors which are believed to be about $0.1 \mu \mathrm{sec}$, the total rms instrumentation threshold is near several tenths of a $\mu$ sec. In view of this, phase fluctuations near this threshold are not believed significant in showing the influence of the other two factors - the propagation path and the received noise.
It has been shown [Watt et al., 1959] that this latter factor produces a noise-induced standard deviation of phase, $S_{\text {avg (noise), where }}$

$$
S_{\mathrm{avg}(\text { noise })} \approx \frac{1}{\sqrt{2}(C / N)^{2}}
$$

and $C$ and $N$ are the effective carrier and noise power at the phase measuring point in the receiving system. In this paper the phase variations induced by noise refer to this last described factor as distinguished from phase variations caused by propagation factors. 


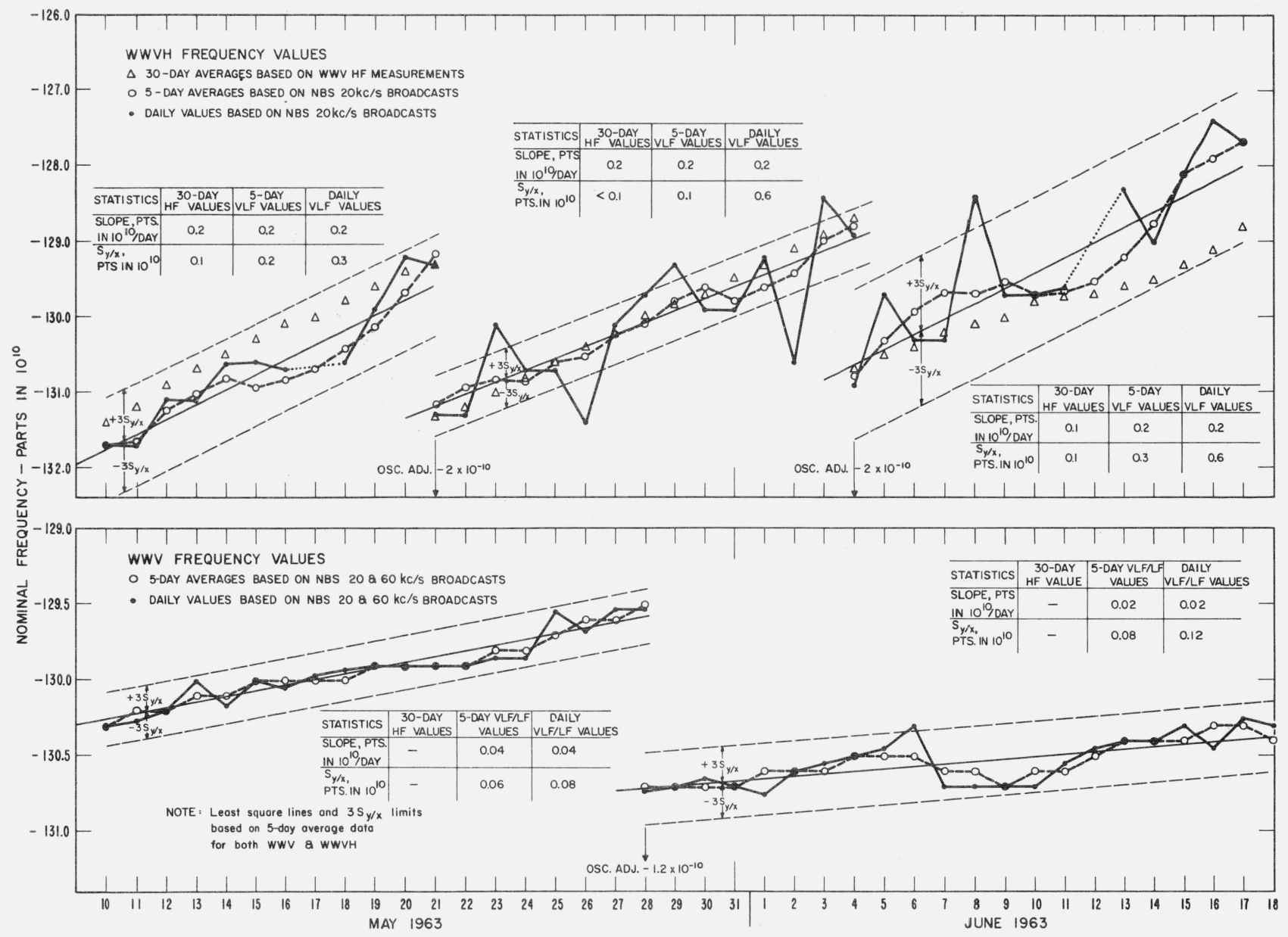

FigurE 14. Comparison of running averages and daily values of $W W V H$ and $W W V$ frequencies.

On the basis of a calculated signal-to-noise ratio for the low-power $20 \mathrm{kc} / \mathrm{s}$ broadcast, the standard deviation of the phase attributable to noise is of the order of 0.5 $\mu$ sec [W att et al., 1959]. A similar figure was obtained for the low power, $60 \mathrm{kc} / \mathrm{s}$ broadcast [Watt, 1964]. Such values seem to be comparable with the records as shown in figures 5 and 6 . Because the signalto-noise ratio is improved by higher radiated power (an increase in power of about 50 and 3000 in the case of the 20 and the $60 \mathrm{kc} / \mathrm{s}$ signals respectively), the phase variation contributed by noise should be considerably reduced with the higher power broadcasts from $\mathrm{Ft}$. Collins.

The precision, $\epsilon$, of frequency comparisons with fixed bandwidth at VLF, using techniques employed in these studies has been shown [Watt et al., 1959] to be

$$
\epsilon \cong \frac{(N / C)^{1 / 2}}{\omega T}
$$

where $N$ and $C$ are the narrow band noise and carrier powers, respectively, $C / N \gg 1, \omega=2 \pi f$, and $T$ is the averaging time, $\epsilon=\frac{\sigma f_{d}}{f}$ where $\sigma f_{d}$ is the standard deviation of the frequency difference between the received frequency and the local standard frequency, $f$. If the precision of the measurement is limited by the carrier-to-noise ratio, then an increase in the carrier level would improve the results, that is, $\epsilon$ is reduced. For the WWVL broadcasts $C / N$ was increased by 50 , and we would expect a reduction in $\epsilon$ of about 7 to 1 , if the precision was limited only by a fixed noise level. With a time varying noise level, the expected improvement would of course be less. In addition, a fixed threshold, consisting both of propagation phase variation and instrument limitations, could limit the improvement obtained by increasing power. It is likely that all of the above effects contribute in causing the observed improvement to be only 2 to 1 .

The short-term stabilities shown in this report approach the limit of precision obtainable with present oscillators, receivers, and recorders in use at WWV and WWVH. Much additional work is required to reduce instrument system errors and to ascertain seasonal and reciprocal path effects. From such work, and by use of comparison oscillators with stabilities better than 1 part in $10^{11}$, it may be possible to deduce the ultimate phase stability of VLF and LF signals [Brady, 1964]. 


\begin{tabular}{|c|c|c|c|c|c|c|c|c|c|c|c|c|c|c|c|c|c|c|c|}
\hline \multirow[b]{3}{*}{ Transmitter } & \multirow[b]{3}{*}{$\begin{array}{l}\text { Receiving } \\
\text { Station }\end{array}$} & \multicolumn{6}{|c|}{ October 1962} & \multicolumn{6}{|c|}{ October 1963} & \multicolumn{6}{|c|}{ June 1963} \\
\hline & & \multicolumn{3}{|c|}{ Day } & \multicolumn{3}{|c|}{ Night } & \multicolumn{3}{|c|}{ Day } & \multicolumn{3}{|c|}{ Night } & \multicolumn{3}{|c|}{ Day } & \multicolumn{3}{|c|}{ Night } \\
\hline & & $\mathrm{S}_{\text {avg }(\mathrm{ph})}$ & n & $\mathrm{k}$ & $\mathrm{S}_{\operatorname{avg}(\mathrm{ph})}$ & $\mathrm{n}$ & $\mathrm{k}$ & $\mathrm{S}_{\operatorname{avg}(\mathrm{ph})}$ & $\mathrm{n}$ & k & $\mathrm{S}_{\operatorname{avg}(\mathrm{ph})}$ & $\mathrm{n}$ & $\mathrm{k}$ & $\mathrm{S}_{\operatorname{avg}(\mathrm{ph})}$ & $\mathrm{n}$ & k & $\mathrm{S}_{\operatorname{avg}(\mathrm{ph})}$ & $\mathrm{n}$ & $\mathrm{k}$ \\
\hline wwvB & wwV & $0.2 \mu \mathrm{s}$ & 18 & 10 & $0.7 \mu \mathrm{s}$ & 13 & 10 & $0.1 \mu \mathrm{s}$ & 19 & 10 & $0.7 \mu \mathrm{s}$ & 13 & 10 & $0.2 \mu \mathrm{s}$ & 15 & 10 & $0.6 \mu \mathrm{s}$ & 11 & 10 \\
\hline \multirow{2}{*}{ WWVL } & wwV & $0.6 \mu \mathrm{s}$ & 19 & 8 & $0.9 \mu \mathrm{s}$ & 13 & 10 & $0.3 \mu \mathrm{s}$ & 18 & 10 & $0.9 \mu \mathrm{s}$ & 13 & 10 & $0.6 \mu \mathrm{s}$ & 17 & 10 & $0.7 \mu \mathrm{s}$ & 10 & 10 \\
\hline & w w VH & - & - & - & - & - & - & $0.7 \mu \mathrm{s}$ & 14 & 10 & $1.8 \mu \mathrm{s}$ & 15 & 10 & $0.8 \mu \mathrm{s}$ & 15 & 8 & 2. $7 \mu \mathrm{s}$ & 13 & 10 \\
\hline \multirow{2}{*}{ NBA } & wwV & $0.8 \mu \mathrm{s}$ & 17 & 10 & $1.3 \mu \mathrm{s}$ & 17 & 10 & - & - & - & - & - & - & $0.6 \mu \mathrm{s}$ & 16 & 10 & $0.7 \mu \mathrm{s}$ & 12 & 10 \\
\hline & w w vH & - & - & - & - & - & - & - & - & - & - & - & - & $0.7 \mu \mathrm{s}$ & 15 & 10 & $1.0 \mu \mathrm{s}$ & 10 & 10 \\
\hline
\end{tabular}

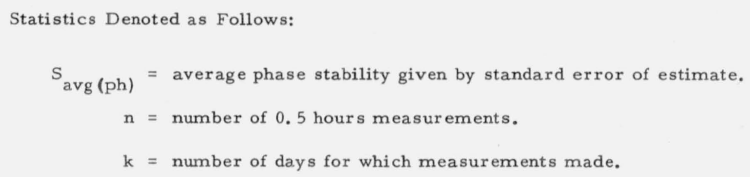



1/ Statistics Denoted as Follows:

\footnotetext{
$\overline{\mathrm{X}}_{\mathrm{di}}$ = grand average of diurnal phase change.

$\mathrm{S}_{\text {avg (di) }}$ average standard deviation of diurnal phase measurements.

$\mathrm{n}=$ number of 0.5 hour measur ement periods per night.

$\mathrm{k}$ = number of days for which measurements made.
}

\subsection{VLF and LF Diurnal Phase Shifts}

Sample diurnal variation measurements were made on the records of WWVL, WWVB, and NBA, and the results are shown in table 2 . (The average diurnal phase change $S_{\text {avg (di), is determined by comparing a }}$ series of phase readings taken during the nighttime portion of the recordings with the average daytime phase level of the preceding and following days.) The data admittedly are sparse as they are essentially single distance measurements for each station during a 2-month period. They do, however, indicate the magnitude of the diurnal changes observed for several different carrier frequencies and propagation distances together with the standard deviations of the measurements. Blackband [1964] has found that, for distances greater than about $4800 \mathrm{~km}$ in the frequency range of 18 to $20 \mathrm{kc} / \mathrm{s}$, the magnitude of the diurnal phase changes tends to increase linearly with distance. 
Wait [1963] has shown that mode theory substantiates Blackband's experimental data. Since some of the measurements given here were taken outside this frequency range, and within the critical second, or higher order, mode distances, and were quite sparse, direct correspondence with Blackband's results may not be expected. (See also [Volland, 1964].)

An additional effect should be considered [Watt, 1964]: considerable variation may occur when diurnal shifts are measured at points which are equidistant but in different directions from the same transmitter, because of differences in day and night phase velocities corresponding to each direction. Also, this directional effect may vary for land or sea paths and with geographical latitude. Such characteristics have been predicted previously by Wait [1962].

The constancy of the diurnal phase shift is an important factor in the day-to-day intercomparisons of frequency standards via low-frequency signals. The imminent improvement in atomic frequency standards [Stoyko, 1964] will necessitate thorough intercomparison of such standards, and, if evaluated by lowfrequency radio signals, the limits introduced by propagation factors must be considered.

The results of this study were made possible through the combined efforts and cooperation of many people. At stations WWV and WWVH the measurements were made by the staffs of Fred Sera and Sadami Katahara, respectively. Catherine Barclay and Vincent Heaton of the NBS, Boulder Laboratories contributed much in the day-to-day calibration and frequency steering work. We have also benefited from many helpful discussions with A. D. Watt, D. D. Crombie, E. L. Crow, and J. F. Brockman. The computer program analysis resulted from the work of Kenneth Yocum, John Devenney, Jean Petersen, and Joan Berube. The NBA recordings made at WWVH were made available by $\mathrm{D}$. D. Crombie. The assistance of Carole Craig in the preparation of this manuscript is gratefully acknowledged.

\section{References}

Beehler, R. E., W. R. Atkinson, L. E. Heim, and C. S. Snider (Dec. 1962), A comparison of direct and servo methods for utilizing cesium beam resonators as frequency standards, IRE Trans. Instr. I-11, No. 3-4, 231-238.

Blackband, W. T. (1964), Diurnal changes in the time of propagation of V.L.F. waves over single mode paths, Propagation of radio waves at frequencies below $300 \mathrm{kc} / \mathrm{s}$, (Pergamon Press), chap 16, 219-229; forward, VI.

Blair, B. E., A. H. Morgan, and L. J. Edlin (1965), Performance characteristics of commercial $\mathrm{Rb}$ atomic frequency standards (private communication).

Box, G. E. P. (1953), Non-normality and tests on variances, Biometrika 40, 318-335.

Brady, A. H. (Mar. 1964), On the long term phase stability of the 19.8 $\mathrm{kc} / \mathrm{s}$ signal transmitted from Hawaii, and received at Boulder, Colorado, Radio Sci. J. Res. NBS 68D No. 3, 283-289.
Burtt, G. J. (Nov. 1963), Observations on phase stability of signals from NBA (18 kc/s) Panama as received in New Zealand, Proc. IEE 110, No. 11, 1928-1932.

CCIR (Nov.-Dec. 1962), Standard frequencies and time signals, Frequency 1, No. 1, 28-31.

Crombie, D. D., A. H. Allen, and M. Newman (May 1958), Phase variations of $16 \mathrm{kc} / \mathrm{s}$ transmissions from Rugby as received in New Zealand, Proc. IEE 105B, 301-304.

Crombie, D. D. (Jan. 1964), Periodic fading of VLF signals received over long paths during sunrise and sunset, Radio Sci. J. Res. NBS 68D, No. 1, 27-34.

Crow, E. L., F. A. Davis, and M. W. Maxfield (1960), Statistics manual, 18, 104, 147-165 (Dover Publications, Inc.).

Davies, O. L. (Ed) (1957), Statistical methods in research and production, 16-17, 61-62 (Hafner Publishing Company).

Fey, R. L., J. B. Milton, and A. H. Morgan (March 17, 1962), Remote phase control of radio station WWVL, Nature 193, No. 4820, 1063-1064.

Looney, C. H., Jr. (Feb. 1961), A very low frequency synchronizing system, Proc. IRE 49, No. 2, 448-452.

Looney, C. H., Jr. (January 1964) VLF utilization at NASA satellite tracking stations, Radio Sci. J. Res. NBS 68D, No. 1, 43-45.

Mockler, R. C., R. E. Beehler, and C. S. Snider (Sept. 1960), Atomic beam frequency standards, IRE Trans. Instr. I-9, No. 2, 120132.

Morgan, A. H., and D. H. Andrews (Apr. 1961), Méthodes et techniques de contrôle des ondes kilométriques et myriamétriques aux Boulder Laboratories, Comité Consultatif pour la Définition de la Seconde auprès du Comité International des Poids et Mesures, $2^{\mathrm{e}}$ session, Annexe 6, (Gauthier-Villars \& $\mathrm{C}^{\mathrm{ie}}$, Paris), 68-72.

Morgan, A. H. (Aug. 1962), Frequency and time calibration services at the Boulder Laboratories of the National Bureau of Standards, NBS Miscellaneous Publication 248, Proc. 1962 Standards Laboratory Conference, 37-43.

Morgan, A. H. (June 1963), Time and frequency broadcasting, ISA Journal 10, No. 6, 49-54.

NBS (July 1957), Experimental standard frequency broadcasts on $60 \mathrm{kc} / \mathrm{s}$, NBS Tech. News Bull. 41, 99-100.

NBS (May 1960), Standard frequency broadcasts on $20 \mathrm{kc} / \mathrm{s}$, Journal des Telecommunications $27,118 \mathrm{f}-119 \mathrm{f}$.

NBS (October 1963), New facilities dedicated for WWVB and WWVL, NBS Tech. News Bull. 47, No. 10, 178-180.

Pierce, J. A. (Dec. 1958), Recent long distance frequency comparisons, IRE Trans. Instr. I-7, No. 3-4, 207-210.

Pressey, B. G., G. E. Ashwell, J. Hargreaves (Mar. 1961), The phase variation of very-low frequency waves propagated over long distances, Proc. IEE 108-B, No. 38, 214-226.

Richardson, J. M. (Jan. 1964), Establishment of new facilities for WWVL and WWVB, Radio Sci. J. Res. NBS 68D, No. 1, 135.

Somerville, P. N. (1958), Tables for obtaining non-parametric tolerance limits, Ann. Math. Stat. 29, 599-601.

Stoyko, A., M. N. Stoyko (Jan.-Feb. 1964) La rotation de la terre et le problème de l'heure au Symposium International des Marées Terrestres et au Congrès International de Chrometrie, Bull Horaire $n^{\circ} 7$ (série 6) 186-187.

Tracor (Mar.-Apr. 1964), Goings-on in LF and VLF, IEEE Digest, Frequency 2, No. 2, 12-13.

Volland, Hans (1964), Diurnal phase variation of VLF waves at medium distances, Radio Sci. J. Res. NBS 68D, No. 2, 225-238.

Wait, J. R. (1962), Electromagnetic waves in stratified media, (Pergamon Press, Ltd., Oxford).

Wait, J. R. (1963), A note on diurnal phase changes of very low frequency waves for long paths, J. Geophys. Res 68, 338-340.

Watt, A. D., and R. W. Plush (July-Aug. 1959), Power requirements and choice of an optimum frequency for a world-wide standard frequency broadcasting station, J. Res. NBS 63D (Radio Prop.), No. 1, 35-44.

Watt, A. D., R. W. Plush, W. W. Brown, and A. H. Morgan (Nov.Dec. 1961), Worldwide VLF standard frequency and time signal broadcasting, J. Res. NBS 65D (Radio Prop.), No. 6, 617-627. Watt, A. D. (May 1964), private communication.

(Paper 69D7-525) 